\title{
Research on Classroom Teaching Model Innovation of Statistics Course under the Background of Blended Learning
}

\author{
LI Yulan \\ Wuhan Business University, Wuhan, 430056, China \\ E-mail: 245428165@qq.com
}

Key words: Blended Learning; Statistics Course; Classroom teaching; Model Construction

\begin{abstract}
In the era of big data, mass data is springing up, whose cleaning and optimization extraction require rigorous statistical thinking and solid statistical theory. Statistics is a methodological science which solves the problems of screening, organizing and analyzing the data. Nowadays, the traditional single partial reform strategy on teaching method cannot meet the requirements of statistical ability training. This article will study the statistics course which is taken the most in the Economics and Management Majors of colleges and analyze the disadvantages of the traditional teaching model. Then this paper will construct a blended teaching model of four dimensions, namely teacher, student, classroom teaching and information learning environment, and analyze the evident advantage to make the statistics be more practical.
\end{abstract}

\section{Introduction}

It is regulated by the State Education Commission that statistics is one of the core courses of economics and management major in Institutions of higher learning. The updating of the data processing technique in the era of big data affects the development of various walks of life and related subjects, especially statistics. [1] The original framework and theory system of statistics have encountered unprecedented shocks and challenges. The problem in statistics teaching is that how to improve the teaching effect of statistics in economics and management major and the ability of the students to solve practical economic problems with statistics theory. [2]Blended learning is a learning strategy and concept which is gradually concerned because of the self-examination of e-Learning and the regression of traditional classroom learning. It combines the advantages of e-learning and traditional classroom learning, and makes up their disadvantages. [3]It aims to provide the better conditions for students, so as to improve their academic ability and comprehensive quality. Blended learning is regarded as a connecting point of traditional teaching and e-learning.

\section{The problems of the traditional statistical teaching}

\section{Focus on the theoretical knowledge and the derivation of formulas}

Nowadays the traditional teaching method is still used in the most economics and management courses, which focus on theories and formula derivation with multi-media, like the content in probability and probability distribution, parameter estimation and hypothesis test. With this method, students are very skilled in theoretical knowledge and formula deduction, but they don't know how to use it in practice. [4]Some students just memorize the formula for their tests. For example, in the chapter of hypothesis testing, students know that the original hypothesis and alternative hypothesis should be put forward, but they don't know how to use them to solve the problems. [5] It is difficult to improve students' ability to analyze and solve practical problems with traditional teaching method. Statistics is a practice-needed course which requires students to analyze practical problems and even make predictions by using the statistical knowledge they have learned, rather than just the derivation of the formula. 


\section{Short class hours on statistics software operation}

Statistical courses are very practical, and whether knowledge can be effectively absorbed depends on the extent of students' subjective initiative. At present, statistics courses do not pay enough attention to practice teaching. [6] Teachers mainly teach the contents of textbooks, rarely organize students to participate in practical projects; and few students can conduct in-depth research and practice independently after class independently. To some extent it also causes the students' enthusiasm to fade away in the abstract and boring statistical theory learning process.

\section{The lack of practical teaching}

The ability training is to cultivate students' ability to discover problems, think and creatively solve practical problems in the process of teaching. Practice teaching is generally divided into two parts, one is in class, and the other is out of class. There is little or no part of practice teaching in class. Most teachers have not worked in statistics in the government or enterprises, so they are "laymen" in practice. There is little combination with practical problems and just theoretical teaching, which is difficult to train students' application ability. In the practice part of training, generally, the teachers just send the data, and students just input it, organize it and analyze it to get the result, which will make the students think that the statistics is about analysis and do not know that how to apply it into practice. So that when students are encountered with the practical economic problems, they do not know how to use the statistical methods to analyze and solve them. The practice teaching is not good enough. The first reason for it is that the teaching hour is too short and some even do not have. The teaching hours of some courses is too short to finish the content, students should learn about 8 chapters at the least and some even 15 to 16 . Teachers even do not have enough times to finish the theoretical contents so they can only make students do the practice after class. The second reason is that practice teaching becomes a mere formality. When colleges arrange students to study in the training base, students just visit like tourists, or do some simple work without learning substantial things.

\section{Classroom teaching model of statistics course under the background of blended learning The definition of blended learning}

Blended learning is a combination of the independent learning in electronic environment and the cooperative learning in classrooms which is based on the characteristics and the contents of the course. It can not only make the teachers play the leading role in classroom learning, but also a new learning way of students to construct knowledge through self-study. It can be said that although the theory of blended learning is first extended in the study of electronic learning, it is also applicable to school teaching, which can be used to guide the study of current teaching reform and information education.

\section{Classroom teaching model of statistics course under the background of blended learning}

Blended learning can be implemented in different ways according to different teaching requirements. According to the characteristics and elements analysis of the statistics course, we can design a blended learning model integrated with information technology and statistics course, as shown in figure 1: 


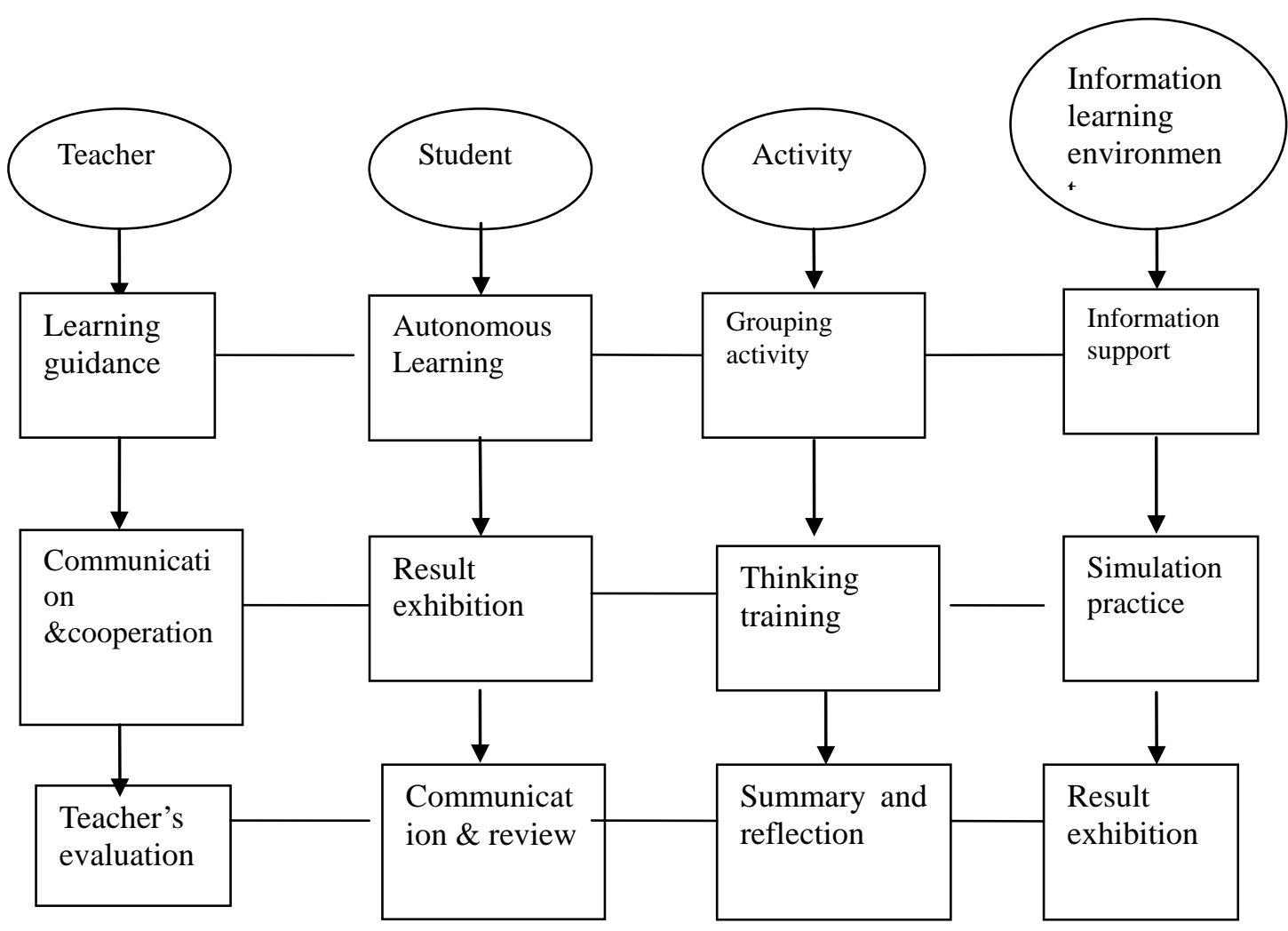

Figure 1. Blended learning model integrated with information technology and statistics course

In this model, the design of teaching (teachers), autonomous learning(students), classroom learning, information learning environment are combined, and the four elements in the model throughout the whole teaching process. According to this model, blended learning is mainly divided into the following four steps:

Step 1: Interpret the content of statistical courses. The key note and the strategy of blended learning will be formulated based on the characteristics of the courses and the students. In another word, the proportion and focus of the $\mathrm{f}$ autonomous learning and classroom learning will be adjusted with the analysis of their advantages and disadvantages.

Step 2: Introduce the cases or problems and put forward the inquiry problem to make students go further by class or e-learning and ask and communicate to form opinion and speak out in teaching. By using network (such as BBS and Blog) means, some students who usually unwilling to communicate in the classroom can also participate in the discussion and learning. Teachers combine all kinds of feedback information, using a variety of teaching methods to demonstrate learning scenarios, analyze and discussion of cases and problems, and guide and encourage students to explore and practice of observation. Students can make further research with the help of information technology, and can also repeat the study and exploration on the problems they don't understand.

Step 3: Guide the students to learning achievements, and help students establish statistical thinking way with the information processing tools (such as PowerPoint, FrontPage etc.). In classroom learning, teachers should act as good guides to construct students' own knowledge; and in students' autonomous learning, they should act as good assistants and help students solve the problems.

Step 4 Students do the exhibition of their works and communicate about it in class, and the teachers make evaluation. And the evaluation tools can be used in students' self-evaluation such as the use of portfolio evaluation method, the students put learning materials into a folder (file bag), which contains the learning notes, assignments, collected information, their own electronic work, learning results, and e-mail, participation in online discussion and Blog learning records, etc., and 
then collected by the teacher to evaluate them.

\section{The advantages of classroom teaching model of statistics course under the background of blended learning}

\section{Strengthen the purpose of learning statistics and arouse students' inner needs}

By using various means, teachers should make students understand that statistics is an indispensable component of the quality of citizens in the future; and show that statistical knowledge is closely related to the world situation, the people's livelihood, and daily life with vivid examples; Show the statistical learning is very important for understanding of national conditions, establish patriotism, patriotic ambition, to cultivate dialectical materialism thought and the scientific outlook on the world, life, the concept of resources, population, environment, which meet the needs of students.

\section{Create appropriate goals and tasks and stimulate students' intrinsic motivation mechanism}

In the process of teaching, teachers should design and put forward some goals and tasks, and help students to solve them, and constantly experience the joy of success, so that its internal incentive mechanism is stimulated to have the intrinsic motivation effect.

\section{Use the transfer effect of motivation and promote students' need of statistical learning}

Due to the special status of statistics in the discipline system, students generally lack motivation to learn statistics. So teachers can consciously associate statistical learning with other students' motivation. For example, make college students daily consumption expenditure, the environment of university campus, the university canteen operation as the investigation content, and the students make research design, questionnaire and select the appropriate method to do the investigation. Then collect data and entry, examine, sort, analyze it to write the final report so that students aware of the importance of statistics in their activities, and to promote the transfer of students' learning motivation.

\section{Conclusion}

In the information era, using the blended learning theory to guide teaching can improve the learning efficiency, enrich the teaching methods, reform the education idea, can make us focus on how to use multimedia and network technology to optimize teaching, and also think about how to make full use of the advantages of various learning environments, ways and resources to promote learning and how to give full play to the leading role of teachers and students' initiative, autonomy and creativity. With the blended learning model the design of teaching (teachers), autonomous learning (students), classroom learning, information learning environment are combined, and the four elements in the model throughout the whole teaching process. The four kinds of forces cooperate and fuse each other to promote the students' application ability and lay a solid foundation of statistics theory and application for the students. Through blended learning, students can learn more actively, and use the Internet more as a tool for learning, rather than a tool for entertainment. They are more skilled in using information technology for autonomous, collaborative learning, and solving practical problems. Blended learning in statistics course helps to cultivate students' learning interest, learning ability, and cooperation ability and innovation spirit.

\section{Acknowledgements}

In this paper, the research was sponsored by Research on Classroom Teaching Model Innovation of under the Background of Blended Learning---Based on Statistics Course, Supported by Wuhan Business School. (Project No. 2016Y008). 


\section{References}

[1] EFFECT OF BLENDED LEARNINGENVIRONMENT MODEL ON HIGH SCHOOL STUDENTS" ACADEMIC ACHIEVEMENT. Yasar Kazu Ibrahim,Demirkol Mehmet. TurkishOnline Journal of Educational Technology. 2014

[2] EFFECT OF BLENDED LEARNINGENVIRONMENT MODEL ON HIGH SCHOOL STUDENTS" ACADEMIC ACHIEVEMENT. Yasar Kazu Ibrahim,Demirkol Mehmet. Turkish Online Journal of Educational Technology . 2014

[3] THE PRIMARY STUDENT TEACHERS'VIEWS ABOUT A BLENDED LEARNING APPLICATION IN A BASIC PHYSICS COURSE. Ekici Fatmal,Kara Izzetl,Ekici Erhanl. Turkish Online Journal of Distance Education . 2012

[4] Blended learning: Uncovering its transformative potential in higher education[J] . D.Randy Garrison, Heather Kanuka. The Internet and Higher Education . 2004 (2)

[5]Blended Learning Applying in University Education. Youtian Qu,Chaonan Wang,Fang Liu,Xiaolei Zhang. ICHL . 2008

[6]Social networks, communication styles, and learning performance in a CSCL community[J] . Hichang Cho, Geri Gay, Barry Davidson, Anthony Ingraffea. Computers \& Education . 2005 (2) 